assay much higher than another with low sand contents. In the case of drugs having an alkaloidal standard it is doubtful if an ash standard should be established. The following table gives results obtained with certain drugs and the standards given by different authorities.

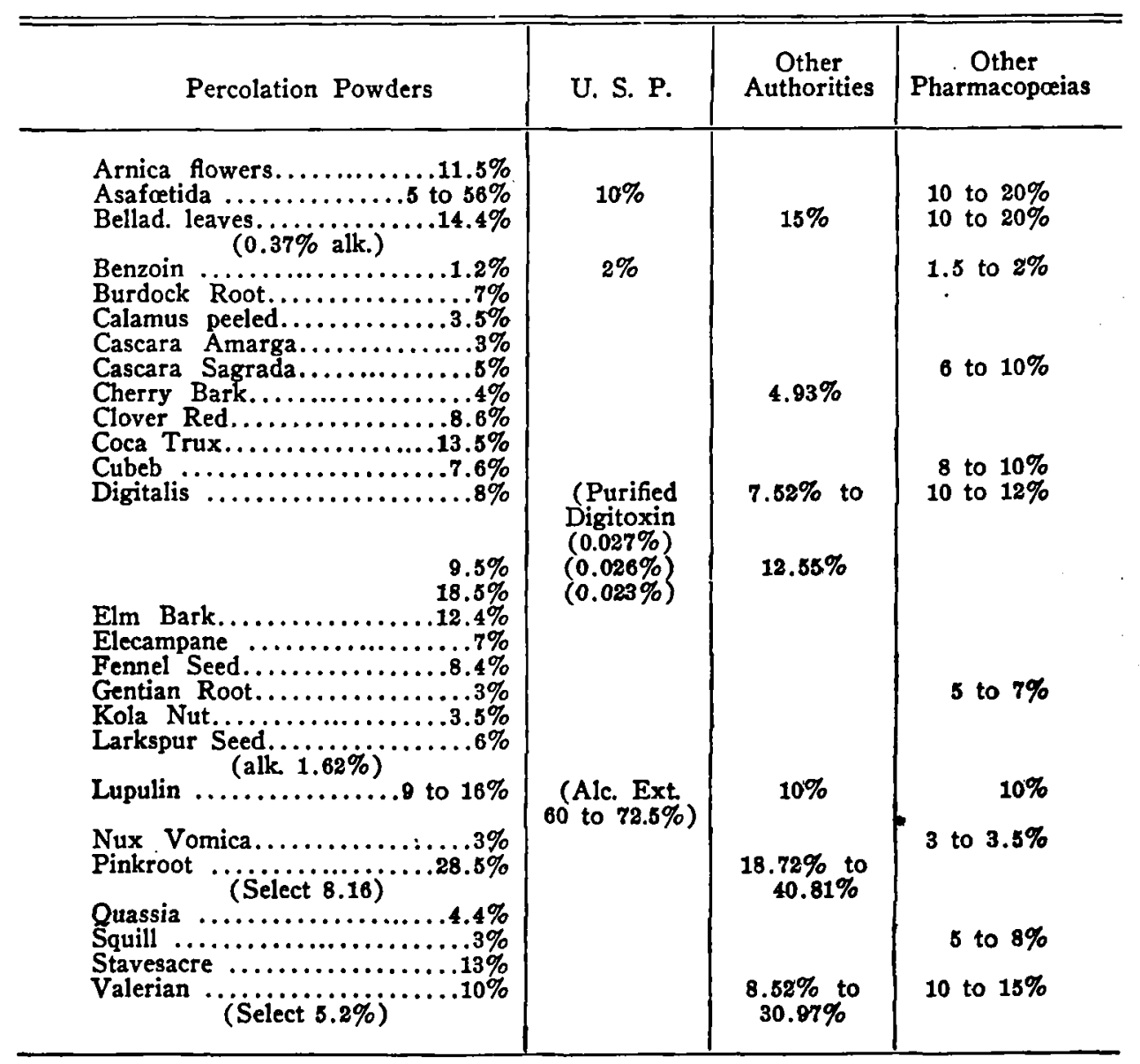

\title{
A FEW DRUGS AND PREPARATIONS SUBMITTED TO U. S. P. QUANTITAVE TESTS.
}

Result of a series of examinations recently made in the laboratories of the College of Pharmacy of the University of Minnesota.

\section{FREDERICK J. WULLING.}

The college has made annually for twenty years now an investigation into the quality of the materia medica of the Northwest and has reported its investigations regularly to the Minnesota State Pharmaceutical Association, in whose proceedings nearly all reports may be found. The reports may or may not merit wider 
publicity, so I submit them for what they are worth. This year's report is much briefer than usual and is arranged in tabular form:

SUMMARY OF RESULTS.

\begin{tabular}{|c|c|c|c|}
\hline $\begin{array}{l}\text { Names of substance } \\
\text { examined }\end{array}$ & $\begin{array}{l}\text { U. S. P. } \\
\text { Require- } \\
\text { ments }\end{array}$ & $\begin{array}{l}\text { Results of } \\
\text { assays in } \\
\text { percentage }\end{array}$ & COMMENTS \\
\hline Dilute Acetic Acid..... & $6 \%$ absolute & $\left.\begin{array}{r}5.85 \\
7.42\end{array}\right]$ & $\begin{array}{l}\text { Only dilute acids were examined. } \\
\text { Pharmacists usually prepare these }\end{array}$ \\
\hline $\begin{array}{l}\text { Dilute Hydochloric } \\
\text { Acid } \ldots \ldots \ldots \ldots \ldots\end{array}$ & $\begin{array}{l}10 \% \text { absolute } \\
\text { acid }\end{array}$ & $\left.\begin{array}{r}6.78 \\
11.34\end{array}\right\}$ & $\begin{array}{l}\text { by diluting the stronger acids and } \\
\text { if these are not of the required } \\
\text { strength the dilute acids vary from }\end{array}$ \\
\hline Dilute Sulphuric Acid.. & $\begin{array}{l}\text { 10\% absolute } \\
\text { acid }\end{array}$ & $\begin{array}{l}10.57 \\
10.70 \\
11.00\end{array}$ & $\begin{array}{l}\text { sayed and standardized, which is } \\
\text { seldom done. The samples exam- } \\
\text { ined met the requirements fairly } \\
\text { well. }\end{array}$ \\
\hline $\begin{array}{l}\text { Aromatic Sulphuric } \\
\text { Acid .............. }\end{array}$ & $\begin{array}{l}20 \% \text { absolute } \\
\text { acid }\end{array}$ & $\begin{array}{l}14.51 \\
16.85 \\
17.80\end{array}$ & $\begin{array}{l}\text { I have rarely found a sample that } \\
\text { tested } 20 \% \text {. }\end{array}$ \\
\hline Ammonia Water... & $\begin{array}{l}10 \% \text { by } \\
\text { weight of } \\
\text { NH, }\end{array}$ & $\begin{array}{r}5.30 \\
6.88 \\
7.75 \\
7.84 \\
13.32\end{array}$ & $\begin{array}{l}\text { These samples were bought in } \\
\text { five and ten-cent lots from Minne- } \\
\text { sota drug stores and were labeled in } \\
\text { each case "Ammonia Water." Phar- } \\
\text { macists claim they must meet the } \\
\text { competition of the department and } \\
5 \text { and } 10 \text { cent stores for a cheap } \\
\text { household ammonia. They err, how- } \\
\text { however, in using the official title. }\end{array}$ \\
\hline $\begin{array}{r}\text { Stronger Ammonia } \\
\text { Water } \ldots . . . \ldots \ldots \\
\end{array}$ & $\begin{array}{l}28 \% \text { of } \\
\mathrm{NH}_{8}\end{array}$ & $\begin{array}{l}23.00 \\
26.20\end{array}$ & $\begin{array}{l}\text { The sample assaying } 23 \% \text { was } \\
\text { taken from a freshly opened car- } \\
\text { boy. }\end{array}$ \\
\hline Spirit of Nitrous Ether. & $\begin{array}{l}\text { 4\% Ethyl } \\
\text { Nitrite }\end{array}$ & $\begin{array}{l}2.14 \\
2.26 \\
2.57 \\
3.42\end{array}$ & $\begin{array}{l}\text { It is very rare indeed that sam- } \\
\text { ples are found that meet the full } \\
\text { U. S. P. requirements. }\end{array}$ \\
\hline $\begin{array}{c}\text { Syrup of Ferrous } \\
\text { Iodide } \ldots \ldots \ldots \ldots\end{array}$ & $5 \%$ & $\begin{array}{l}\text { 5 samples, } \\
\text { all below } \\
\text { standard }\end{array}$ & $\begin{array}{l}\text { Two of the samples were pre- } \\
\text { pared with great care in our own } \\
\text { aboratories. They did not assay } \\
5 \% \text {. This has been our previous } \\
\text { experience. I doubt whether the } \\
\text { oftcial formula will yield exactly a } \\
5 \% \text { product. }\end{array}$ \\
\hline $\begin{array}{l}\text { Sodium Bicarbonate.... } \\
\text { Potassium Bitartrate... } \\
\text { Potassium Iodide....... } \\
\text { Solution Magnesium } \\
\text { Citrate ............... } \\
\text { Seidlitz Powders....... }\end{array}$ & & $\begin{array}{l}1 \text { sample of } \\
\text { each assayed } \\
\text { satisfactorily }\end{array}$ & \\
\hline
\end{tabular}

